\title{
UMA LEITURA DE THE MACHINE STOPS, A DISTOPIA TECNOLÓGICA DE E. M. FORSTER
}

\author{
Helvio Moraes
}

Uma das raras incursões de E. M. Forster no gênero da ficção científica, o conto The Machine Stops (A Máquina Para) foi publicado pela primeira vez em 1909, no Oxford and Cambridge Review, e republicado em seu segundo livro de contos, The Eternal Moment, em 19281. Privilegiamos, neste estudo, a relação entre os gêneros literários da utopia e da ficção científica, buscando uma base teórica em autores que dialogam, retomam e, porvezes, fazem uma revisãocrítica dos estudos pioneiros de Darko Suvin, publicados durante a década de setenta. Suvin abre novas perspectivas no estudo da ficção científica ao defender sua forte ligação com o pensamento utópico, a partir de pressupostos marxistas, percebendo nos dois tipos de escrita uma "forma de emancipação do pensamento que mantém vivas a esperança por justiça social e a igualdade” (CSICSERY-RONAY JR, p. 118).

Além da ideia de um "parentesco" entre utopia e ficção científica, pelo menos duas outras noções avançadas por Suvin são, até hoje, centrais, para a interpretação de textos de ficção científica: o estranhamento cognitivo e o novum. Em relação ao primeiro conceito, o teórico chama de

$1 \mathrm{O}$ estudo desse texto e sua tradução comentada são o objeto do projeto de pesquisa Homo urbanus: relações entre o homem e a cidade em narrativas do século XX e início do $X X I$, que desenvolvo atualmente junto ao Instituto de Linguagem (IL) da Universidade do Estado de Mato Grosso - Unemat, e no U-Topos - Centro de Pesquisa sobre Utopia (IEL/ Unicamp). 
"straniante" “a representação que nos permite, antes de tudo, reconhecer o objeto, mas ao mesmo tempo o faz parecer estranho". O estranho faz surgir uma "curiosidade pelo desconhecido", esteja este "desconhecido" espacialmente determinado ou projetado noutra dimensão temporal, e nesta curiosidade "se fundem a emoção do saber e a agitação da aventura" (SUVIN, 1985, p. 20). Ainda em relação a este conceito, segundo CsicseryRonay Jr, um texto de ficção científica deve "apresentar aspectos da realidade empírica do leitor, mas que se "tornam estranhos" por meio de uma nova perspectiva que "implica um novo conjunto de normas". Esta remodelagem do familiar tem uma finalidade "cognitiva”, ou seja, o reconhecimento da realidade que ela evoca no leitor é um ganho na compreensão racional das condições sociais de existência" (CSICSERYRONAY JR, p. 118).

O segundo conceito, o de novum, é um tanto mais complexo, pois, como nos mostra Moylan (200o), Suvin a ele se volta constantemente ao longo dos anos 80 e início de 9o, buscando elucidá-lo, às vezes, revisando-o. Primeiramente, podemos afirmar que o novum serve como elemento que relaciona a ficção científica a outros gêneros, como a utopia. Para Suvin, o novum narrativo é

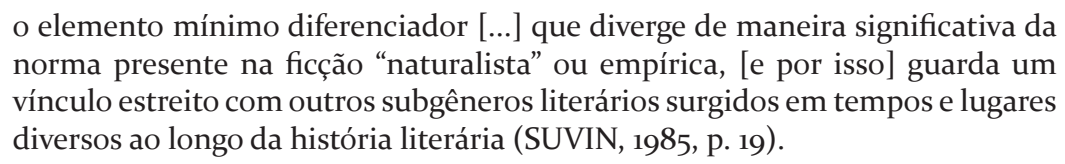

Contudo, mais interessante para nosso trabalho, é perceber o novum como algo que, no texto de ficção científica, provoca o efeito de alteração do mundo ficcional em relação ao mundo em que vivemos. Essa alteração se dá por meio de uma inovação científica ou tecnológica, que causa transformações importantes em todos os âmbitos da vida humana. Nesse sentido, o novum pode ser visto como algo que intervém no processo histórico e é, de certa forma, produzido por tal processo. Isso torna possível a eliminação, na categoria do novum, das intervenções sobrenaturais comuns à literatura fantástica, pois, para Suvin, o novum é racional. Segundo Csicsry-Ronay Jr (2003, p. 119), na prática,

o novum aparece como uma invenção ou uma descoberta em torno da qual as personagens e o ambiente se organizam de modo convincente e historicamente plausível. O novum é produto de processos materiais; produz efeitos que podem ser logicamente percebidos no mundo social, é plausível em termos de lógica histórica, seja na história da tecnociência, seja na história de outras instituições sociais". 
Como o próprio Suvin (1998, p. 76) afirma, "nascido na história e julgado na história, o novum tem um caráter indiscutivelmente histórico". Da mesma forma, "a realidade ficcional correlativa ou mundo possível [...], apesar de todos os seus deslocamentos e disfarces, sempre corresponde aos sonhos ou pesadelos de um grupo sociocultural específico [...]”. Para concluir essa parte introdutória, gostaríamos de lembrar a distinção que Moylan, seguindo o pensamento de Suvin, faz entre o novum e o pseudonovum. A característica do novum é a oposição, a do pseudo-novum é a conformidade. Ao invés de oferecer uma explicação consoladora para - e conforme - o estado de coisas existente, o novum formula um problema, questiona tal estado: o "novum não é a "novidade" reificada produzida pelo capitalismo [...]; ao contrário, ele é a força dialética que media as possibilidades materiais e históricas e a consciência e a ação subjetivas comprometidas com tais possibilidades" (MOYLAN, 2000, p. 58).

Devemos levar em conta, porém, que no texto de Forster, como veremos, o novum opera negativamente, por se tratar de uma distopia. Nela, o mundo se torna extremamente mecanizado, o desenvolvimento científico e tecnológico parece ter chegado a um nível de máxima ascensão, a ponto de a vida humana se encontrar em dependência absoluta de uma Máquina global que atende - mas também regula, controla - as necessidades físicas e espituais do homem.

A ciência se transforma aos poucos numa espécie de nova religião. Os habitantes deste lugar situado nas entranhas da terra recorrem sempre ao Livro da Máquina - irônica imagem que é sempre retomada e que alude à substituição da Bíblia e, consequentemente, a certos princípios éticos e morais que vão sendo abandonados à medida que a nova organização política se impõe -, onde se encontram compendiados os motivos pelos quais a Máquina deve ser estimada ${ }^{2}$, todas as respostas para qualquer malestar físico ou emocional que possa acometer uma pessoa. Como objetos

2 Na verdade, no início da novela, as personagens têm um certo pudor em reconhecer que a adoram com ardor religioso: "Sentada na cama, ela o tomou [o Livro] reverentemente em suas mãos. Olhou em volta da sala reluzente, como se alguém a pudesse estar observando. Então, um tanto envergonhada, um tanto alegre, murmurou: "Oh, Máquina! Oh, Máquina!, e levou o volume aos seus lábios. Três vezes o beijou, três vezes inclinou sua cabeça, três vezes sentiu o delírio da aquiescência” (FORSTER, p. 7). Com o passar do tempo, uma forma de religião é restabelecida sem qualquer constrangimento: "Aqueles que, por muito tempo, tinham adorado em silêncio, agora começaram a falar. Descreviam a estranha sensação de paz de que se viam possuídos quando manuseavam o Livro da Máquina [...]. 'A Máquina', exclamavam, 'nos alimenta e nos veste e nos abriga [...]; é a amiga das ideias e inimiga da superstição: a Máquina é onipotente, eterna; abençoada é a Máquina" (p. 26). 
de adoração, os avanços científicos, se é que podemos denominá-los avanços, não são colocados em questão, assim como não é questionada a ordem social instaurada pelo aperfeiçoamento tecnológico.

O homem é isolado (ou exilado) do convívio humano tal como ainda o experimentamos. $\mathrm{O}$ conto se inicia justamente com essa imagem de isolamento e letargia, e podemos, já aqui, atentar para a noção de estranhamento cognitivo proposta por Suvin:

Imagine, se puder, um pequeno cômodo, em forma hexagonal, como um alvéolo de colméia. Não recebe luz por nenhuma janela ou lâmpada. Ainda assim, se enche de uma radiação suave. Não há aberturas para ventilação e, no entanto, o ar é fresco. Não há instrumentos musicais. Ainda assim, no momento em que começo minha reflexão, tal cômodo vibra com sons melodiosos. Uma poltrona no centro, a seu lado uma escrivaninha - esta é toda a mobília. E, sentada na poltrona, uma massa de carne envolvida por um pano - uma mulher, medindo aproximadamente um metro e sessenta de altura, com uma face tão branca como um cogumelo. A ela pertence este pequeno aposento" (FORSTER, p. 3).

Este pequeno cômodo, misto de sala e quarto, é o espaço onde Vashti passa toda sua vida. O único contato (voluntário) que tem com o mundo exterior se dá por meio de um tubo acústico (speaking tube) e de uma tela, uma espécie de placa circular, em que vê a imagem da pessoa com quem fala. Não há contato físico entre as pessoas, "o desastrado sistema de encontros públicos há muito tempo havia sido abandonado; nem Vashti nem sua audiência saiam de seus aposentos" (FORSTER, p. 6). Vashti sente-se confortável em meio a todo um aparato tecnológico capaz de lhe garantir a sobrevivência e a possibilidade de se dedicar a atividades do intelecto:

Havia botões e interruptores por todo lugar - botões para pedir comida,
música, roupa. Havia o botão para o banho quente que, ao ser pressionado,
fazia surgir uma grande bacia de (imitação) mármore, repleta até a borda com
um líquido morno desodorizado. Havia o botão para o banho frio. Havia o
botão que fornecia literatura. E havia, obviamente, botões por meio dos quais
ela se comunicava com seus amigos. O cômodo, embora não contivesse nada,
estava em contato com tudo o que lhe importava no mundo (FORSTER, p. 6).

Sua relação com estes amigos não é exatamente o que entendemos por amizade. São pessoas cujos interesses, dentro de um mundo tecnológico virtual, coincidem de alguma forma com seus próprios interesses. Com nenhum deles compartilha seus anseios, suas angústias, suas esperanças, seus temores. Aliás, Vashti não vive nenhum destes sentimentos. No mundo subterrâneo, os habitantes parecem viver num eterno presente, indiferentes à passagem do tempo. Diante de qualquer 
necessidade, basta consultar o Livro da Máquina. Quando não sentem mais vontade de viver, solicitam ao Estado que lhes seja concedido o direito à eutanásia.

Portanto, a personagem central desta narrativa não se coloca em contraste com o mundo em que vive. É seu filho, Kuno, quem descobrirá a decadência dessa ordem social governada pela máquina. Kuno não aceita o conhecimento transmitido pelos aparelhos implantados em sua cela, situada no extremo oposto geográfico de sua mãe. Quer ver as estrelas, quer ter a experiência de um contato mais direto com as pessoas e com o mundo (enquanto tal experiência é abominada por Vashti) e, assim, num gesto de rebeldia, descobre uma saída para a superfície da Terra. Lá, encontra muito rapidamente um pequeno grupo de homens, que vive refugiado nas campinas, por entre a vegetação, esperando que a civilização do mundo subterrâneo entre em colapso. Em sua viagem, Kuno descobre que a "Máquina parou" e que o processo de decadência é irreversível, pois

a Humanidade, em seu desejo por conforto, tinha se excedido. Ela tinha explorado as riquezas da natureza em demasia. Quieta e complacentemente, estava afundando na decadência, e o progresso passou a significar o progresso da Máquina (FORSTER, p. 27).

Quando todo o aparato tecnológico entra em pane, esses "mortosvivos" não conseguem buscar refúgio em lugar algum e morrem soterrados pelos escombros da cidade que termina por sucumbir.

Embora Forster tenha afirmado numa coletânea de contos, datada de 1947, que A Máquina Para havia sido escrita em oposição a alguns textos de Wells - mais precisamente, "a reaction to one of the ealier heavens of H. G. Wells3" -, em que este atribui um caráter mais positivo à tecnologia, podemos perceber, na conclusão da novela, que sua visão não é cerradamente cética, pelo menos em relação à possibilidade de continuação da vida, num nível em que as relações humanas se restabeleçam e resgatem certos princípios éticos que haviam sido renunciados com o advento da Máquina. Em meio ao caos, mãe e filho se reencontram e, pela primeira vez, se beijam e choram:

Eles choravam pela humanidade, aqueles dois, não por eles mesmos. Não podiam suportar que isso fosse o fim. Antes que o silêncio fosse completo, seus corações se abriram, e eles compreenderam o que havia sido importante

3 Forster apud Summers (1983, p. 256). 
na terra. O homem, a flor de toda a carne, a mais nobre de todas as criaturas visíveis, o homem que uma vez havia criado deus à sua imagem e espelhado sua força nas constelações, o belo homem nu estava morrendo, sufocado nas vestes que havia tecido (FORSTER, p. 33).

O conto termina com um diálogo entre Vashti e Kuno, em que este confirma ter conhecido os Desabrigados, homens que foram excluídos do mundo governado pela Máquina:

'Eu os vi, falei com eles, amei-os. Eles estão se escondendo em meio às samambaias até que nossa civilização pare. Hoje eles são os Desabrigados. Amanhã...'

'Oh, amanhã - algum tolo ligará a Máquina novamente, amanhã.' 'Nunca', disse Kuno, 'nunca. A humanidade aprendeu sua lição.' (FORSTER, p. 33-4).

O ceticismo de Forster se apresenta na crítica que faz a certas tendências, latentes ou não, da vida inglesa (e europeia) do início do século $\mathrm{XX}$ : o isolamento do indivíduo, o esfacelamento das relações humanas, o crescente desenvolvimento tecnológico e industrial, a crença desmedida no progresso, o distanciamento do homem em relação à natureza, a repressão da faculdade instintiva e o consequente enrijecimento das convenções sociais, a consciência de classe, etc. Todos esses elementos eram vistos pelo romancista como efeitos de "um enorme movimento econômico que tem conduzido o mundo todo, inclusive a Grã-Bretanha, da agricultura ao industrialismo", movimento que Forster admitia odiar, como nos lembra Stevenson (2007, p. 209)4. Isso talvez ajude a explicar o papel de relevo que o cenário pastoril e as vastas paisagens solitárias têm em seus primeiros romances e, principalmente, nos contos. Em vários casos, a relação direta com as forças elementares do mundo natural ${ }^{5}$ é

4 A frase citada por Stevenson é extraída de uma palestra proferida por Forster em 27 de abril de 1944, na Universidade de Glasgow, intitulada “The Development of English Prose between 1918 and 1939".

5 Forster referia-se a seus contos como fantasies. De acordo com Godfrey (1968, p. 9), na maioria dos contos, fantasy, "geralmente um acontecimento de tipo sobrenatural, irrompe em meio, e em desafio, à realidade cotidiana, e as personagens, de acordo com o grau de sua sensibilidade espiritual, reagem a ela”. Para Summers (1983, p. 238), "os enredos de quase todos os contos relatam a emancipação de personagens, geralmente crianças e adolescentes, do aprisionamento das convenções sociais. Estes contos frequentemente giram em torno de genius loci, da apreensão de um determinado espírito do lugar e da apreciação das forças elementares da natureza”. Há certa controvérsia entre os estudiosos de Forster sobre o real significado do termo fantasy em sua obra. O mesmo Godfrey faz uma leitura que defende e ressalta a presença de um elemento místico nos contos, 
representada como um momento de revelação e autoconhecimento para personagens que entram em contraste com um grupo social que manifesta um comportamento ilusoriamente civilizado, geralmente acompanhado de um intelectualismo árido ${ }^{6}$. Em The Machine Stops, os papeis de Kuno e Vashti ilustram essa ideia.

O primeiro, como aquele que vislumbra no mundo dos Desabrigados o possível resgate de uma ideia de humanidade que quase se perdera. Forster faz Kuno enunciar, num futuro longínquo e representando uma grande redescoberta, um princípio humanista de que era (e sempre foi) ardente defensor, embora percebesse que, em sua época, aos poucos se extinguia ou se achava em crescente descrédito: "o Homem é a medida. Essa foi minha primeira lição. Os pés humanos são a medida para a distância, suas mãos são a medida para a posse, seu corpo é a medida para tudo o que é forte e digno de ser amado e desejado" (FORSTER, p. 17). Já fizemos menção à bela passagem em que o narrador retrata a morte do homem nu sufocado pelas vestes que ele mesmo havia tecido. Ela diz respeito a um aspecto do humanismo forsteriano, que se formula numa noção de individualismo em contraste com qualquer tipo de repressão totalitária. Em What I Believe, um famoso ensaio escrito às vésperas da Segunda Guerra Mundial (1938), Forster expõe tal noção (e tal contraste), retomando a imagem da nudez humana como elemento apriorístico da organização social:

O ditador-herói pode macerar seus cidadãos até tornarem-se todos parecidos, mas não pode fundi-los em um só homem. Isso está além de seu poder. Ele pode ordenar que se mesclem, mas eles são obrigados a nascer separados e

\footnotetext{
"um aspecto da excelência de Forster que os críticos julgaram inconveniente perseguir" (GODFREY, 1968, p. 1), e Head (2007, p. 85) nos chama atenção para o fascínio exercido por escritores "que desejavam combinar realismo e fantasia, o natural e o sobrenatural", no momento em que o conto se legitima como "nova forma literária em fins do século XIX e início do XX", e afirma que "em parte, Forster estava em conformidade com o estilo literário corrente". Cremos, porém, que a presença do fantástico em The Machine Stops, ao contrário do advento das forças do "não visto" (unseen), aproxima-se mais daquilo que Suvin define como estranhamento cognitivo e da própria construção ficcional já ditada pela tradição utópica, com sólidas implicações políticas e sociais, antes de tudo.

6 Como a crítica implícita que faz aos intelectuais de Cambridge (Forster estudou no King's College) em Maurice, assim como em outros textos. Ardis (2007, p. 66) nos afirma que, em Forster, eles são “conhecidos pela 'estupidez' de seus corações, pelo seu interesse em sufocar ou disfarçar qualquer demonstração emotiva em nome da 'civilização', e por uma intelectualidade que, deliberada e implacavelmente se distancia dos aspectos emocionais e sensuais da experiência”. Tais qualidades apresentam-se claramente em Vashti, como veremos.
} 
a morrer separados, e, devido a estes dois inevitáveis termos, estarão sempre fugindo dos trilhos totalitaristas. A memória do nascimento e a expectativa da morte estão sempre guardadas no íntimo do ser humano, separando-o de seus companheiros e, consequentemente, tornando-o capaz de se relacionar com eles. Nu eu vim ao mundo, nu deverei dele sair! Uma coisa muito boa, de fato, pois me faz lembrar que estou nu sob minha camisa, qualquer que seja sua cor (FORSTER, 1938) ${ }^{7}$.

Esta individualidade macerada por um poder totalitário que, no conto, encontra em Kuno uma obstinada oposição, se vê representada na atitude indolente de Vashti, em sua completa inatividade física, que sugere uma submissão resignada à Máquina e a um obscuro Comitê Central, que mantem em funcionamento o complexo aparato tecnológico do qual depende toda a estrutura social daquela "colmeia". Na verdade, trata-se da leitura que o romancista faz de um elemento central do gênero utópico. Forster é um dos primeiros escritores a formular, em chave distópica, a crise desse paradigma: a conjunção entre a individualidade e as aspirações do corpo social, motivadas e reguladas pelo aparato estatal. Tentando, portanto, uma aproximação à teoria de Suvin, a questão pode ser formulada da seguinte forma: como pode ser compreendido o novum, quando usado pelo poder político como forma de regular a sociedade?

O pensamento de Platão sobre a relação cidadão/coletividade teve uma vasta fortuna em nossa tradição literária e está na base do mundo outro criado nos escritos utópicos clássicos. Especificamente sobre a relação entre o individual e o coletivo, a realização pessoal e o bem comum, podemos citar uma passagem central do terceiro livro da República, em que Sócrates questiona:

"Há um maior mal para o Estado que aquele que o desmembra e de um produz muitos? Ou um maior bem do que aquele que o articula e faz com que seja uno?" [...] "Ora a comunhão dos prazeres e das dores não é o que o articula quando os cidadãos, na medida do possível, juntamente se alegram e se entristecem pelos mesmos ganhos e pelas mesmas perdas?” [...] “Tornar privado esse sentimento acaso não os divide? Quando uns estarão muito alegres e os outros muito tristes a respeito dos mesmos acontecimentos que afetam o Estado e os cidadãos no Estado?" [...] "No Estado em que o maior número de cidadãos, a respeito da mesma coisa e segundo o mesmo sentido, diz juntamente é meu e não é meu não haverá um ótimo governo?" (PLATÃO, 462A-C).

7 No conto, há outra passagem que corrobora esta ideia, numa fala de Kuno: "Eu senti que a humanidade existia, e que existia sem roupas. Como posso explicar isto? Estava nua, a humanidade parecia nua, e todos esses tubos e botões e maquinários não vieram ao mundo conosco, nem nos seguirão lá fora, nem têm tanta importância enquanto estamos aqui" (FORSTER, p. 18). 
Na República, Platão objetiva construir um Estado ideal e, à sua imagem, um homem ideal: o cidadão que internaliza, materializa, os valores da cidade. Há uma analogia entre o homem e a polis, representada pela metáfora do Estado como um corpo humano. Desta forma, este corpo menor (o homem) reflete os princípios - para dizermos com Platão, encarna a alma - do corpo maior (a cidade). O percurso do filósofo grego é idear a cidade perfeita, com suas instituições políticas, econômicas e sociais, para, daí, formar um cidadão que incorpore os valores de tais instituições. Nas palavras de Sócrates: "devemos considerar, em primeiro lugar, a cidade, passando depois ao indivíduo" (PLATÃO, p. 176). As inúmeras paixões humanas desencadeiam personalidades muito díspares e idiossincráticas, e devem, por isto, ser submetidas ao escrutínio de uma razão organizadora, que as regule e as direcione rumo ao bem comum. $\mathrm{O}$ objetivo é dar forma a uma sociedade unificada, em que os anseios daqueles que a compõem convirjam na totalidade de aspirações comuns. Como a perfeição da cidade pressupõe, necessariamente, a total estabilidade de suas instituições, não há espaço para a livre exposição de opiniões e desejos individuais que, de uma forma ou de outra, entrem em confronto com os fundamentos desta organização social. Por este motivo, a utopia clássica adotará a figura do grande legislador, uma reelaboração da imagem do reifilósofo platônico, aquele que, se o compararmos ao homem do famoso mito, sai da caverna, contempla a verdadeira luz e, quando retorna ao convívio de seus companheiros, os instrui e os orienta.

Em vários sentidos, Morus segue os passos de Platão. Citamos um curto trecho sobre a educação dos cidadãos:

O mestre, na Utopia, emprega toda a sua experiência e talento em imprimir, na alma ainda tenra e impressionável da criança, os bons princípios que são a salvaguarda da república. A criança que recebeu o gérmen desses princípios guarda-os em sua carreira de homem, tornando-se mais tarde um elemento útil à conservação do Estado. É o vício que destrói os impérios e o vício é engendrado pelas más opiniões (MORUS, p. 145).

Outros elementos, dispersos no relato moreano, corroboram o princípio de uma espécie de "sacrifício da realização pessoal" em prol de uma satisfação coletiva. Como exemplo, podemos lembrar que suas refeições, feitas em grandes refeitórios em que os mais velhos discutem "questões de grande seriedade", mas também "gostam de ouvir o que os mais jovens têm a dizer" (MORUS, 1999, p. 99), são, elas também, momentos dedicados à instrução, ao aprendizado dos valores mais caros à comunidade política. 
Berriel, ao comentar um famoso estudo de Raymond Trousson, observa que esta tendência da utopia clássica ao dirigismo absoluto tende necessariamente a negar todo individualismo: "O utopismo pressupõe o intervencionismo radical, sendo o indivíduo sempre subordinado às exigências de ordem e de equilíbrio total." Paradoxalmente, o utopista "sacrifica o indivíduo para proteger a instituição criada originalmente para o homem” (BERRIEL, 2003).

Sabemos que a utopia clássica sofrerá um profundo descrédito ao longo do século XX. Em oposição a esta imagem de Estado, cujas instituições se fazem compreender com clareza e se refletem no espírito de seus habitantes, teremos a imagem sombria de um Estado injusto, imperscrutável, em que os homens são lançados à margem da vida pública, não se reconhecem como parte de uma espécie de organismo social. Ao contrário do mundo de Morus, os mundos outros do século XX se orientam para a destruição da experiência coletiva. Quando não, tal experiência é representada como uma doença, manifestação de vivências esvaziadas de sentido, mesmo que não conscientes, como a de Vashti, por mais que seu filho se esforce em fazê-la enxergar:

\footnotetext{
'Você não pode ver, não podem todos vocês palestrantes ver, que somos nós que estamos morrendo e que aqui embaixo a única coisa que de fato vive é a Máquina? Nós criamos a Máquina para fazer nossas vontades, mas não podemos forçá-la a fazer nossas vontades agora. Ela nos roubou o sentido de espaço e o sentido do tato. Ela manchou toda relação humana e reduziu o amor a um ato carnal, paralisou nossos corpos e nossos desejos, e agora nos compele a adorá-la. [...] Apenas existimos como os corpúsculos de sangue que fluem por suas artérias, e se ela pudesse funcionar sem nós, deixaria- nos morrer' (FORSTER, p. 21).
}

Como na utopia clássica, também temos em Forster a rígida interferência do Estado como regulador da sociedade. Do Estado ainda se originam as leis, os preceitos que regulam a vida dos homens. Mas, na distopia, sua face não se mostra, nem mesmo como simulacro da imagem de homem da qual ele mesmo é criador e formador. Naquela, ao menos em tese, o fim do estado é também a realização humana. Nesta, o Estado éo fim de si mesmo. Cria homens para devorá-los numa espécie de mecanismo incompreensível - que é produto de uma "razão enlouquecida".

Forster, portanto, será um dos primeiros autores - e há quem veja nisto um gesto premonitório - a nos revelar "o medo da opressão totalizante", que faz da distopia o "oposto especular da própria utopia" (BERRIEL, 2006, p. 96). 


\section{Segundo Berriel (2006, p. 98),}

a distopia [...] é o alongamento do perfil das utopias construídas a partir de proposituras abstratas, e não de metáforas ou analogias. $\mathrm{O}$ controle social absoluto, a partir das consciências [...], conduziu a uma variante de utopias [...] que fornecerá os elementos para a futura distopia. [...] A noção de perfectibilidade social, então, não nasce - nem poderia nascer - de uma experiência humana concreta, geradora de problemas solúveis, mas nasce incontaminada pela História, nasce como constructo ideal, em que a dimensão empírica do homem está removida.

A questão da legitimidade do conhecimento empírico, da relação direta entre o homem e o mundo como forma autêntica de experiência, é bastante enfatizada ao longo de todo o texto de Forster ${ }^{8}$. Ela contrasta com um dos preceitos ditados pela Máquina:

Cuidado com as ideias de primeira mão! [...] Ideias de primeira mão não existem de fato. Elas nada mais são do que impressões físicas produzidas pelo amor e pelo medo e, sobre uma base tão grosseira, quem poderia erigir uma filosofia? Deixem que suas ideias sejam de segunda mão e, se possível, de décima mão, pois desse modo elas estarão bem longe daquele elemento perturbador - a observação direta. [...] Com o tempo, [...] surgirá uma geração que transcenderá os fatos, as impressões, uma geração absolutamente incolor, uma geração Será fisicamente livre da mácula da personalidade" (FORSTER, p. 25).

Vashti empenha-se constantemente em ter "ideias" que, na verdade, são mesmo impessoais, vestígios de uma "racionalidade estéril, hábil

8 Várias são as passagens que abordam o tema da experiência direta, sustentado com obstinação por Kuno, enquanto sua mãe busca dissuadi-lo. Em alguns momentos, como no início do conto, ele surge de modo subentendido: "'Eu quero ver você não através da Máquina', disse Kuno. [...] 'Oh, cale-se! [...] Você não pode dizer nada contra a Máquina'. [...] 'Eu vejo algo semelhante a você nessa placa, mas não vejo você' (FORSTER, p. 3-4); “[...] a Máquina não transmitia nuanças de expressão. Ela somente dava uma ideia geral das pessoas” (p. 5). Todo o relato de Kuno sobre como conseguiu chegar à superfície terrestre é, obviamente, pontuado por descrições de observações diretas e desempenho físico, culminando com a altiva e, ao mesmo tempo, trágica constatação de que "[...] não tenho remédio, ou, ao menos, um: dizer e tornar a dizer que eu vi as colinas de Wessex do mesmo modo como Alfred as viu quando venceu os dinamarqueses" (p. 21). Por outro lado, a viagem que Vashti é obrigada a fazer para visitar o filho só lhe traz aborrecimentos, pelo fato de ser "dominada pelos terrores da experiência direta" (p. 8) o tempo todo. Ela se sente incomodada pelas janelas da aeronave que, quando abertas, obrigam-na a "ver a horrível terra parda, e o mar, e as estrelas" (p. 4), e que somente existem porque "quando as aeronaves foram construídas, o desejo de olhar diretamente para as coisas ainda existia no mundo" (p. 11). 
e plausível apenas na superfície" (GODFREY, 1968, p. 15). Aceita sem hesitação o princípio da "ideia de décima mão"9 e, com brilhante ironia, Forster denuncia a vacuidade dessa atitude, numa cena em que Vashti, sobrevoando a Terra, olha pela janela da aeronave, constata que " "não há ideias aqui', e esconde a Grécia atrás de uma persiana de metal” (FORSTER, p. 14). De acordo com Rose (1970, p. 39), Vashti, por rejeitar "a observação direta, prontamente se ajusta aos crescentes defeitos da Máquina, quando esta começa a se desintegrar. O desarranjo final inevitavelmente traz o desastre para aqueles desprovidos de individualidade e iniciativa".

O mundo forsteriano será construído sobre essa imagem de uma razão enlouquecida. O exercício da racionalidade, se busca nos apresentar uma face benfazeja e promissora na utopia, quando levado ao extremo de banalizar a experiência imediata, de isolar o homem de sua realidade objetiva e corromper as relações sociais, pode esconder uma outra face, que a distopia tecnológica de Forster nos revela: a de um mundo intolerante e de um poder opressor. A distopia nos apresenta a face oculta desta representação do mundo outro tomando como base uma ideia de homem, uma ideia de Estado, e não o homem a partir de sua experiência histórica, dotado ao mesmo tempo de razão e paixões, sem a necessidade de que um lado sufoque o outro ${ }^{10}$, algo que Forster parece intuir por meio de Kuno, o jovem filósofo ou poeta, que se rebela e se aventura pelo mundo, e descobre uma proto-civilização que pode fazer renascer um sentimento de solidariedade, o desejo de uma forma superior de existência em comum.

A convicção de que, embora em inevitável processo de decadência, a humanidade "aprenderá sua lição", ainda que num futuro distante, é algo que ocupa um lugar central no pensamento do jovem Forster e está presente em outro texto de juventude, publicado um ano após sua distopia:

9 Este princípio é enunciado por um célebre palestrante na parte final do conto: "Não aprendam nada sobre esse assunto meu: a Revolução Francesa. Aprendam, ao invés, o que eu penso que Enicharmon pensou do que Urizen pensou do que Gutch pensou do que Ho-Yung pensou do que Chi-Bo-Sing pensou do que Lafcadio Hern pensou do que Carlyle pensou do que Mirabeau disse sobre a Revolução Francesa” (FORSTER, p. 25).

10 Nesse ponto - e nos perguntamos se há outros -, parece haver uma convergência entre o pensamento de Forster e o de William Morris, cuja utopia, News from Nowhere, foi publicada quase duas décadas antes de The Machine Stops. O longo percurso realizado por William Guest, o protagonista do romance de Morris, sugere a possibilidade do homem aprender e amadurecer a partir de uma aceitação e uma melhor compreensão de seus próprios sentimentos e paixões, o que Abensour (1990) definirá como uma "maiêutica passional". 
Howards End. Medalie (2002, p. 7) afirma que o romance "apresenta a modernidade como uma crise e até mesmo como um apocalipse", e menciona uma passagem em que o narrador parece reiterar, em alguns pontos, as últimas falas de Kuno:

Falar mal de Londres não está mais em moda. A terra como culto artístico teve seus dias de glória e a literatura do futuro provavelmente ignorará o campo e procurará inspiração na cidade. Podemos entender essa reação. De Pã e das forças elementais o público já ouviu bastante - eles parecem vitorianos, ao passo que Londres é georgiana -, e os que amam sinceramente a terra talvez tenham que esperar muito antes que o pêndulo a ela volte (FORSTER, 1993, p. 115) ${ }^{11}$.

É possível comparar o movimento secreto e paciente dos Desabrigados em The Machine Stops a essa imagem do movimento pendular de retorno à terra em Howards End. Dissemos acima que o papel dos Desabrigados sugere o resgate de certos traços da vida humana que haviam desaparecido com o advento da modernidade. Em Howards End, segundo Medalie (2002, p. 9),

O oscilar do pêndulo oferece a possibilidade de um movimento contrário, sugerindo que a marcha cruel rumo à dissolução não é inevitável. Contudo, não é provável que o retorno ocorra sob as condições do presente: no mundo moderno, as forças da modernidade prevalecerão e "aqueles que se preocupam com a terra" não terão outra arma senão a paciência.

O quadro se torna mais completo se levarmos em conta a imagem com que Forster encerra seu conto, representando a destruição final da civilização moderna por meio de um de seus símbolos mais expressivos, a aeronave:

Uma aeronave introduzira-se através do vomitório [i.e., túnel de acesso ao mundo subterrâneo] em direção a uma plataforma em ruínas. Ela penetrava a terra, explodindo com estrondo à medida que caia, rasgando galeria após galeria com suas asas de aço. Por um momento, eles viram as nações dos mortos e, antes que a eles se juntassem, pedaços do céu imaculado.

11 A seguir, faz uma descrição de Londres, em que a compara a um "coração que indubitavelmente bate, mas sem pulsação de humanidade” (FORSTER, 1993, p. 115). Outras comparações que faz e o modo como descreve a cidade faz com que nesta passagem ela se assemelhe significativamente ao mundo de Vashti. 
262 - Remate de Males 32.2

\section{REFERÊNCIAS BIBLIOGRÁFICAS}

ABENSOUR, Miguel. O Novo Espírito Utópico. Campinas: Edunicamp, 1990.

ARDIS, Ann. "Hellenism and the Lure of Italy" In: BRADSHAW, David (ed.). The Cambridge Companion to E. M. Forster. Cambridge: Cambridge University Press, 2007.

BERRIEL, Carlos Eduardo Ornelas. "A Utopia como Gênero, ou as Possibilidades de uma Tipologia Utópica” In: VIII Simposio Internacional de Comunicación Social, 2003, Santiago, Cuba.

. "Utopie, dystopie et histoire". Morus - Utopia e Renascimento, no 3. Campinas: Gráfica Central da Unicamp, 2006.

CSICSERY-RONAY JR., Istvan. "Science Fiction/Criticism" In: SEED, David (ed.). A Companion to Science Fiction. Oxford: Blackwell Publishing Ltd., 2005.

FORSTER, E. M. Howards End. Trad. Ruy Jungmann. Rio de Janeiro: Ediouro, 1993. . The Machine Stops. Disponível em: http://www.feedbooks.com.

."What I Believe” (1938). Disponível em: http://www.skeptic.ca/EM_Forster_ What_I_Believe.htm.

GODFREY, Denis. E. M. Forster's Other Kingdom. New York: Barnes \& Noble, Inc., 1968.

HEAD, Dominic. "Forster and the Short Story" In: BRADSHAW, David (ed.). The Cambridge Companion to E. M. Forster. Cambridge: Cambridge University Press, 2007.

MEDALIE, David. E. M. Forster's Modernism. Palgrave MacMillan, 2002.

MORE, Thomas. Utopia. Trad. Jefferson Luiz Camargo e Marcelo Brandão Cipolla. São Paulo: Martins Fontes, 1999.

MOYLAN, Tom. “'Look into the Dark': On Dystopia and the Novum” In: PARRINDER, Patrick (ed.). Learning from Other Words - Estrangement, Cognition and the Politics of Science Fiction and Utopia. Liverpool: Liverpool University Press, 2000.

PLATÃO. A República. Trad. Leonel Vallandro. Rio de Janeiro: Ediouro, 2000. . Repubblica. Trad. R. Radice. In: REALE, Giovanni (ed.). Platone - Tutti gli scritti. Milano: R.C.S Libri, 2005.

ROSE, Martial. E. M. Forster. London: Evans Brothers Ltd., 1970.

STEVENSON, Randall. "Forster and Modernism" In: BRADSHAW, David (ed.). The Cambridge Companion to E. M. Forster. Cambridge: Cambridge University Press, 2007.

SUMMERS, Claude J. E. M. Forster. New York: Frederick Ungar Publishing Co., Inc., 1983.

SUVIN, Darko. Le metamorfosi della fantascienza. Bologna: Il Mulino, 1985. . Positions and Presuppositions in Science Fiction. Kent: Kent University Press, 1988. 